\title{
ALAT BANTU PENGGERINDAAN SLIDEWAYS MESIN BUBUT
}

\author{
Fajar Aswin ${ }^{1)}$, Nanda Pranandita ${ }^{2)}$ Ary Kiswanto ${ }^{3)}$, Syahdan Hafiz ${ }^{4)}$, Zaenal $^{5)}$ \\ ${ }^{1,2,3,4)}$ Program Studi Teknik Perawatan dan Perbaikan Mesin, \\ Politeknik Manufaktur Negeri Bangka Belitung Sungailiat, Bangka Belitung, Indonesia \\ 1) Fajar.aswin@gmail.com
}

\begin{abstract}
Lathe is a tool that rotates the work-piece about an axis of rotation to perform various operations such as cutting, sanding, knurling, drilling, or deformation, facing, turning, with tools that are applied to the work-piece to create an object with symmetryabout that axis. There are several considerations that affect the lathe to work well, especially geometrical deviations that affect the quality degradation of the product in terms of shape and dimensions. One of the wear on the slide-way of the lathe can affect geometric aberrations. This paper discusses the design and manufacture of grinding tools to fix the lathes bed that can erode three slide-way planes in a single process to achieve flatness and square alignment with one another. The research method used is the experimental method by collecting the data needed to design the tool through literature study and direct observation to the lathe, then the data is processed to obtain the specification of the tool that will be designed by design method based on Verien Deutche Ingenieuer (VDI) 222, the design result is then continued with the machining and fabrication process; before assembling, parts of the auxiliary equipment are tested in accordance with the design function indicator; the last stage is testing the tool as a whole to know the achievement of the tool against a predetermined goal. Based on the results of the grinding experiment on the three slideway planes with a feed depth of $0.03 \mathrm{~mm}$, the average flatness and alignment values are $0.02 \mathrm{~mm} /$ $300 \mathrm{~mm}$ and $0.07 \mathrm{~mm} / 300 \mathrm{~mm}$, respectively. Based on the ISO 1708 standard on the tolerance of geometrical deviations, the grinding results have not allowed the tolerance. Still need more research about the influence of wear of grinding wheels to the grinding results.
\end{abstract}

Keywords: lathe machine, geometric deviation, grinding tools, flatness and alignment, VDI 222 method.

\begin{abstract}
Abstrak
Mesin bubut merupakan mesin perkakas yang digunakan untuk memotong benda kerja yang berbentuk silinder. Ada beberapa pertimbangan yang mempengaruhi mesin bubut agar bekerja dengan baik, terutama penyimpangan geometris yang mempengaruhi penurunan kualitas pada produk dalam hal bentuk dan dimensi. Salah satunya adalah keausan pada slideway mesin bubut. Makalah ini membahas perancangan dan pembuatan alat bantu penggerindaan untuk memperbaiki slideway mesin bubut yang dapat mengikis tiga bidang slideway dalam satu kali proses untuk mencapai kerataan dan kesejajaran bidang satu dengan yang lainnya. Adapun metode penelitian yang digunakan adalah metode eksperimental dengan cara mengumpulkan data yang diperlukan untuk merancang alat melalui studi literature maupun observasi langsung ke mesin bubut, kemudian data diolah untuk mendapatkan spesifikasi alat bantu yang akan dirancang dengan pendekatan metode perancangan berdasarkan Verien Deutche Ingeniuer (VDI) 222, hasil rancangan kemudian dilanjutkan proses permesinan dan pabrikasi; sebelum dirakit, bagian - bagian alat bantu diujicoba fungsinya sesuai dengan indikator fungsi rancangan; tahapan terakhir adalah pengujian alat bantu secara keseluruhan untuk mengetahui ketercapaian alat terhadap tujuan yang telah ditetapkan. Berdasarkan hasil percobaan pengerindaan pada ketiga bidang slideway dengan kedalaman pemakanan sebesar 0,03mm, rata - rata nilai kerataan dan kesejajaran didapat sebesar 0,02 mm/300 mm dan 0,07mm/300 $\mathrm{mm}$. Berdasarkan standar 1501708 tentang toleransi penyimpangan geometris, hasil penggerindaan belum masuk toleransi. Masih perlu penelitian lebih lanjut tentang pengaruh keausan batu gerinda terhadap hasil penggerindaan.
\end{abstract}

Kata kunci: Mesin bubut, penyimpangan geometris, alat bantu penggerindaan, kerataan dan kesejajaran, Metode VDI 222.

JURNAL MANUTECH Vol. 9, No. 2, Desember 2017: 76-88 


\section{PENDAHULUAN}

Ada beberapa pertimbangan yang mempengaruhi mesin bubut agar bekerja dengan baik yaitu usia pemakaian mesin, beban yang diterima mesin, penyimpangan geometris dan tindakan perawatan dan perbaikan. Usia pemakaian mesin bisa mempengaruhi performa mesin bubut, semakin tua usia mesin maka semakin menurun juga performa mesin bubut dan perawatan pada mesin harus ditingkatkan. Beban yang diterima pada mesin akan mempengaruhi kondisi mesin, jika beban yang diterima diatas maksimum mesin akan cepat rusak serta beban yang bekerja pada mesin tidak merata akan menurunkan performa mesin. Sedangkan penyimpangan geometris yang terjadi pada komponen mesin akan mempengaruhi produk yang dihasilkan, penyimpangan geometris dipengaruhi keausan pada bidang kontak.

Slideway merupakan salah satu bagian mesin bubut yang mengalami penyimpangan geometris seiring dengan usia pemakaian mesin. Untuk mengembalikan kondisi slideway maka maka diperlukan tindakan perbaikan. Ada beberapa cara menggerinda slideway mesin bubut, yaitu manual atau menggerinda dengan tangan, portable dan mesin. Proses penggerindaan secara manual ditunjukan pada Gambar 1.1. [1] dimana acuan utama yang digunakan adalah landasan slideway itu sendiri sehingga tingkat kesejajaran antara slideway terhadap spindel utama diragukan.

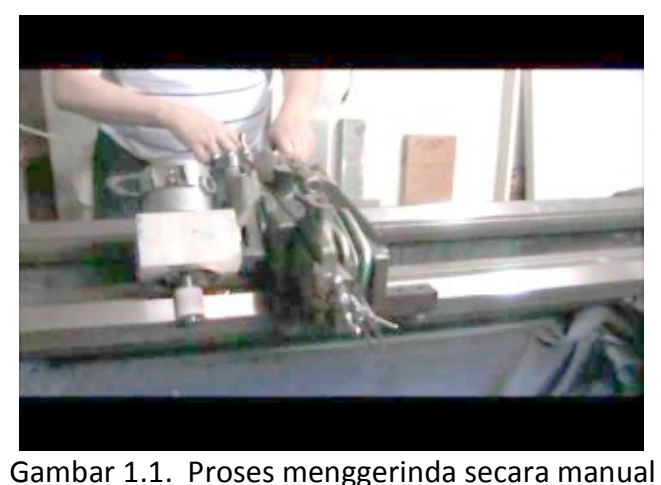

Pada penggunaan mesin gerinda slideway portable [2], yaitu mesin yang memiliki 4 buah roller bearing sebagai landasan yang bertumpu pada slideway langsung sehingga titik acuan akan sulit dicapai (tergantung dengan kondisi bearing) serta memerlukan penyetelan yang ektra. Gambar 1.2 menunjukan contoh paten tentang gerinda portable untuk slideway mesin bubut.

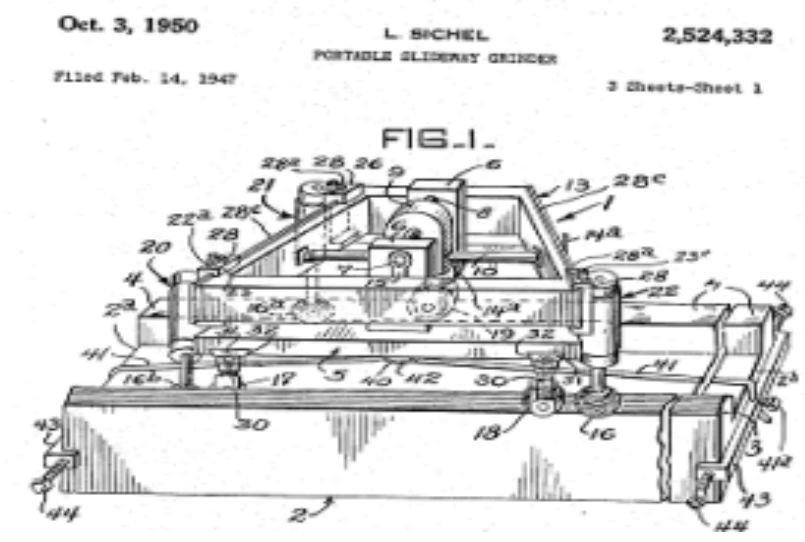

Gambar 1.2. Portable salideway grinder

Selain itu, jika menggunakan slideway grinding machine [3,4], suatu mesin gerinda yang memiliki 2 sistem penggerindaan dan bergerak secara bersamaan dalam menggerinda sepanjang slideway mesin bubut dan menggunakan rel untuk menggerakan mesin secara horizontal. Seperti yang ditunjukan pada Gambar 1.3, penggunaan mesin gerinda ini sangat membantu untuk perbaikan slideway 
mesin bubut karena hanya memerlukan satu kali proses, akan tetapi untuk investasi mesin ini sangat mahal dan jika slideway diperbaiki ditempat lain, memerlukan waktu dan biaya yang tidak sedikit, khususnya bagi industri menengah atau yang sedang berkembang.

Berdasarkan kelemahan atau masalah diatas, perlu dibuat sebuah alat bantu penggerindaan slideway mesin bubut yang dapat menggerinda 3 bidang dalam 1 proses. Untuk mencapai tujuan, dibuatlah perumusan masalah yang fungsinya untuk mengarahkan penyelesaian masalah menjadi lebih spesifik, yaitu Bagaimana merancang dan membuat alat bantu penggerindaan slideway mesin bubut yang dapat digunakan untuk 3 bidang slidway dalam 1 proses serta bagaimana pengaruh hasil penggerindaan terhadap kerataan, kedataran dan kesejajaran pada slideway?.

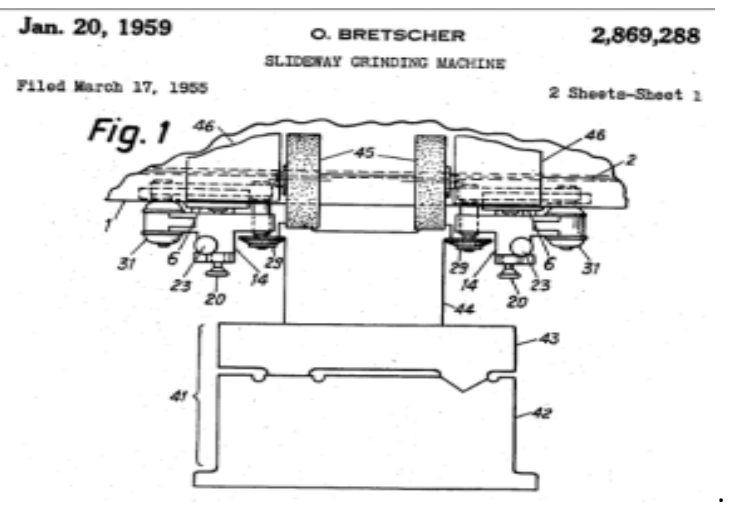

Gambar 1.3 Slideway grinding machine

Untuk membatasi masalah tidak melebar, maka dalam penelitian ini mesin bubut yang menjadi bahan ujicoba adalah mesin bubut yang mempunyai panjang slideway mulai dari 1,4m- 2,7m dan lebar tailstock mulai dari $22.5 \mathrm{~cm}-35 \mathrm{~cm}$; tipe mesin bubut yang digunakan adalah merk Ajax type AJ.200E$1150 \mathrm{~mm}$; Motor yang digunakan pada alat penggerindaan slideway menggunakan motor DC.

\section{LANDASAN TEORI}

\subsection{Gerinda}

Gerinda merupakan alat yang berfungsi untuk mengikis permukaan benda menjadi lebih rata dan mengurangi nilai kekasarannya. Awalnya gerinda ditujukan untuk menggerinda benda kerja berupa logam yang keras seperti besi dan baja. Menggerinda dapat pula untuk mengasah benda kerja seperti pisau dan pahat, atau dapat juga untuk membentuk benda kerja seperti merapikan hasil pemotongan, merapikan hasil las, membentuk lengkungan pada benda kerja yang bersudut, menyiapkan permukaan benda kerja untuk dilas, dari semua itu untuk mendapatkan hasil kerja yang baik.

Mesin gerinda (grinding machines) merupakan sebuah alat yang digunakan untuk proses pemotongan logam secara abrasive melalui gesekan antara material abrasive dengan benda kerja/logam. Selain untuk memotong logam/benda kerja sesuai ukuran, proses gerinda ini juga untuk finishing (memperhalus dan membuat ukuran yang akurat pada permukaan benda kerja). Menggerinda dapat juga digunakan untuk mengasah benda kerja seperti pisau dan pahat, serta dapat juga digunakan untuk menyiapkan permukaan benda kerja yang akan dilas. Mesin gerinda terutama dirancang untuk menyelesaikan suku cadang yang permukaannya silindris, datar atau penyelesaian permukaan dalam.

\subsection{Slideway mesin bubut}

Guideway /slideways /bedways adalah salah satu contoh elemen mesin yang penting mesin bubut. Fungsi utama dari slideways adalah untuk memastikan bahwa alat potong atau alat mesin dari elemen operasi bergerak sepanjang jalur yang telah ditentukan serta membawa benda kerja bersama dengannya. Dan semua bagian yang bergerak seperti bedways akan mengalami keausan yang dapat menurunkan ketepatan, kecepatan dan efisiensi kerja, bahkan pergerakannya tidak lancar.

Lintasan luncur digunakan sebagai jalur (pengarah) jalannya bagian-bagian mesin yang bergerak seperti meja mesin, meja peluncur, carriage dan lain-lain. Suatu lintasan luncur harus dapat memenuhi persyaratan sebagai berikut : 
Harus memiliki kekakuan yang tinggi.

Permukaan slideways harus memiliki akurasi yang lebih besar dan surface finish.

Harus memiliki akurasi pergerakan yang tinggi. Hal ini memungkinkan jika penyimpangan dari pergerakan jalur aktual elemen operasi dari jalur normal yang telah ditentukan adalah minimum.

Harus tahan lama dan daya tahan tergantung pada kemampuan slideways untuk menahan akurasi awal dari proses manufaktur dan pergerakan.

$>\quad$ Gaya gesek yang bekerja pada permukaan slideway harus rendah untuk menghindari keausan.

\subsection{Metode Penelitian}

Metode penelitian yang digunakan dalam penelitian ini ditunjukan pada gambar 2.1 dibawah ini:

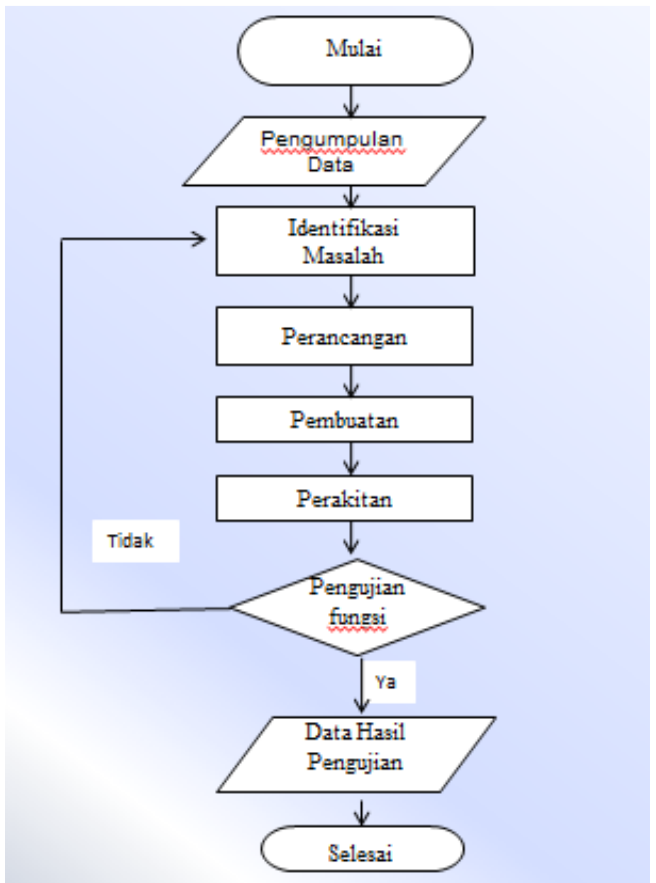

Gambar 2.1 Diagram Alir Metode Pelaksanaan

Tahapan awal yang dilakukan adalah mengumpulkan informasi dari berbagai sumber literature (buku, jurnal, paten, thesis, desertasi, etc) yang berkaitan dengan perancangan alat bantu penggerindaan slideway mesin bubut. Tahapan selanjutnya adalah mengumpulkan data tentang spesifikasi teknik meja mesin bubut baik melalui observasi lapangan, manual book mesin maupun pencarian data digital (online) yang selanjutnya akan dijadikan acuan dalam merancang spesifikasi dimensi alat bantu, rpm gerinda, dan dimensi batu gerinda.

Kemudian tahapan dilanjutkan dengan perancangan alat sesuai dengan hasil pada tahapan sebelumnya. Proses preancangan alat menggunakan metode perancangan VDI 222 untuk mendapatkan desain rancangan alat yang optimal sesuai dengan tuntutan spesifikasi alat yang akan dibuat. Dalam proses perancangan ini, alat bantu dibagi menjadi beberapa fungsi bagian untuk memudahkan dalam pembuatan part - part alat bantu seperti yang ditunjukan pada diagram fungsi pada gambar 2.2. 


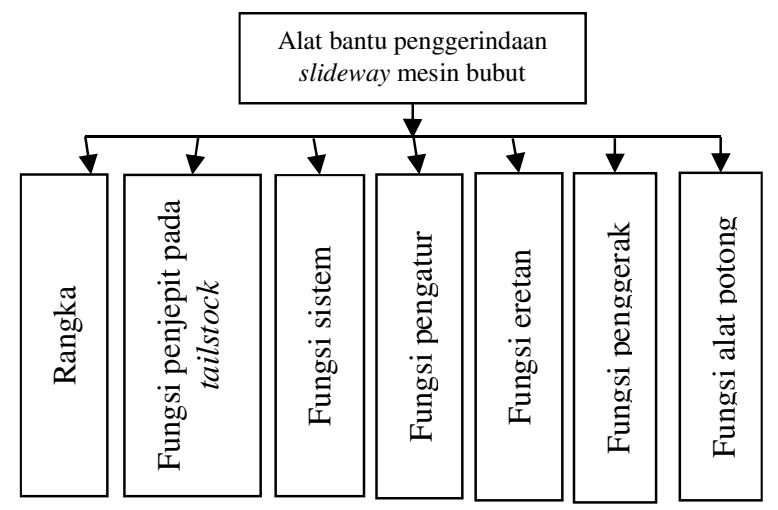

Gambar 2.2 Diagram Fungsi Alat Bantu

Setelah perancangan bagian - bagian alat, tahapan selanjutnya adalah pembuatan bagian bagian alat baik menggunakan proses permesinan bubut, frais, bor maupun proses pabrikasi logam seperti pengelasan, pembengkokan pelat, dll. Tahapan terakhir adalah perakitan alat dan pemasangan pada media uji untuk proses pengujian fungsi dari alat dan pengambilan data.

\section{HASIL DAN PEMBAHASAN}

Hasil perakitan alat bantu penggerindaan slideways mesin bubut ditunjukan pada gambar 3.1. Setelah melakukan pembuatan alat tahap selanjutnya pengujian fungsi. Pengujian fungsi bertujuan untuk memastikan apakah semua fungsi sistem bekerja dengan baik dan mencari kesalahan yang mungkin terjadi pada system. Hasil pengujian fungsi dari bagian - bagian alat bantu penggerindaan slideway mesin bubut ditunjukan pada tabel 3.1.

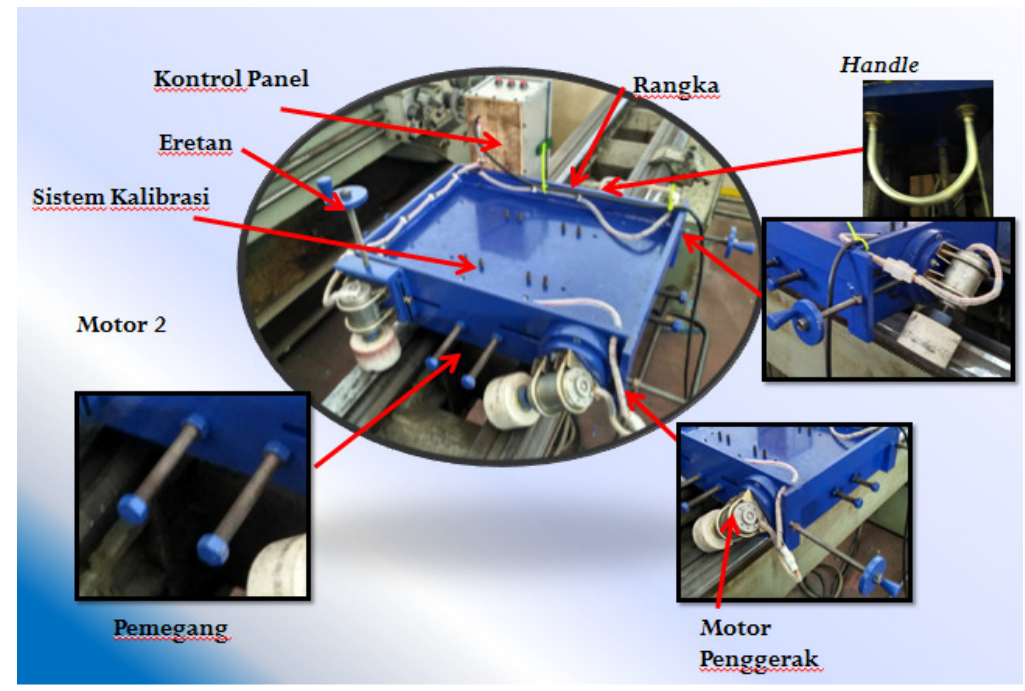

Gambar 3.1 Alat Bantu Penggerindaan Slideway mesin bubut 
Tabel 3. 1 Hasil Pengujian Fungsi

\begin{tabular}{|c|c|c|c|}
\hline NO & BAGIAN & INDIKATOR FUNGSI & FUNGSI \\
\hline \multirow{3}{*}{1} & \multirow{3}{*}{ Kerangka } & Dudukan peny udut dapat dipasang pada kerangka & Tercapai \\
\hline & & Eretan dapat dipasang di kerangka & Tercapai \\
\hline & & Sistem kalibrasi dapat dipasang di kerangka & Tercapai \\
\hline \multirow{2}{*}{2} & \multirow{2}{*}{$\begin{array}{l}\text { Penjepit } \\
\text { Kerangka }\end{array}$} & Pengikatan erat pada Tailstocks & Tercapai \\
\hline & & Dapat meny etel posisi alat & Tercapai \\
\hline 3 & $\begin{array}{c}\text { Sistem } \\
\text { Kalibrasi }\end{array}$ & pengkalibrasian dapat dilakukan dengan mudah & Tercapai \\
\hline \multirow{2}{*}{4} & \multirow{2}{*}{ Penyudut } & $\begin{array}{l}\text { Batu gerinda dapat meny udut pada slideway bidang } \\
\text { "V" bagian dalam }\end{array}$ & Tercapai \\
\hline & & $\begin{array}{l}\text { Batu gerinda dapat meny udut pada slideway bidang } \\
\text { "V" bagian luar }\end{array}$ & Tercapai \\
\hline \multirow{2}{*}{5} & \multirow{2}{*}{ Eretan } & $\begin{array}{l}\text { Eretan dapat naik turun untuk pemakanan bidang } \\
\text { datar. }\end{array}$ & Tercapai \\
\hline & & $\begin{array}{l}\text { Eretan dapat digerakan secara horizontal pada } \\
\text { pemakanan meny udut. }\end{array}$ & Tercapai \\
\hline 6 & $\begin{array}{l}\text { Putaran } \\
\text { motor }\end{array}$ & $\begin{array}{l}\text { Motor dapat memutar batu gerinda sesuai dengan } \\
\text { standar Rpm yang disesuaikan pada spesifiksi pada } \\
\text { batu gerinda }\end{array}$ & Tercapai \\
\hline
\end{tabular}

\subsection{Data Kondisi Awal}

Setelah melakukan pengujian fungsi tahap selanjutnya mengambil data hasil pengujian.. Adapun tujuan dari pengambilan data adalah untuk mengetahui hasil penggerindaan terhadap kerataan, kesejajaran dan kedataran terhadan bidang acuan pengukuran. Pada pengujian ini menggunakan dial indicator sebagai alat ukur dengan cara meletakannya pada bagian utama alat dan menempelkan jarum dial indicator pada bidang yang akan di ukur. Selanjutnya mengambil data kedataran pada bidang acuan dengan menggunakan dial indicator yang diletakan pada alat dan jarum dial indicator di tempelkan pada bidang yang akan diukur, pengecekan sepanjang $30 \mathrm{~cm}$ pada slideway mesin bubut dimana di titik " $\mathrm{A}$ " sepanjang $10 \mathrm{~cm}$, titik " $\mathrm{B}$ " sepanjang $20 \mathrm{~cm}$ dan di titik " $\mathrm{C}$ " sepanjang $30 \mathrm{~cm}$. Ilustrasi pengambilan bidang acuan kedataran ditunjukan pada gambar 3.2. Pengambilan data awal kedataran sebelum pemakanan menggunakan plat sebagai bahan uji coba pada slideway mesin bubut dapat dilihat pada Tabel 3.2.

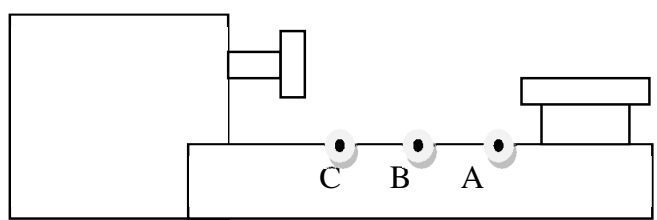

Gambar 3. 2 Iliustrasi Penentuan Bidang Acuan

Tabel 3. 2 Data Kondisi Kedataran Awal

\begin{tabular}{cccc}
\hline \multirow{2}{*}{ Bagian } & \multicolumn{3}{c}{ Awal } \\
\cline { 2 - 4 } & A & B & C \\
\hline $\begin{array}{c}\text { "V" } \\
\text { dalam }\end{array}$ & $0,09 \mathrm{~mm}$ & $0,08 \mathrm{~mm}$ & $0,08 \mathrm{~mm}$ \\
\hline "V" Luar & $0,11 \mathrm{~mm}$ & $0,12 \mathrm{~mm}$ & $012 \mathrm{~mm}$ \\
\hline $\begin{array}{c}\text { Bidang } \\
\text { datar }\end{array}$ & $0,12 \mathrm{~mm}$ & $0,11 \mathrm{~mm}$ & $0,11 \mathrm{~mm}$ \\
\hline
\end{tabular}

Data pada tabel dianggap sebagai bidang acuan untuk melihat pengaruh hasil penggerindaan terhadap kerataan dan kesejajaran. pengambilan data awal dengan mengukur kedataran bidang terhadap posisi alat bantu. 


\subsection{Hasil Pengujian Kerataan Bidang "V" Bagian Dalam}

Dari hasil pengukuran slideway bidang "V" bagian dalam slideways nilai yang didapatkan pada pengukuran awal sepanjang $10 \mathrm{~cm}$ dengan hasil pengukuran setelah diproses dengan kedalaman pemakanan $0,03 \mathrm{~mm}$ adalah sebesar $0,06 \mathrm{~mm}$, selanjutnya pada titik $20 \mathrm{~cm}$ dengan hasil pengukuran akhir dengan kedalaman pemakanan $0,02 \mathrm{~mm}$ adalah sebesar $0,06 \mathrm{~mm}$, setelah itu pada titik $30 \mathrm{~cm}$ dengan hasil pengukuran akhir dengan pemakanan $0,01 \mathrm{~mm}$ adalah sebesar $0,07 \mathrm{~mm}$, dengan demikian bidang yang di uji tidak sejajar. Hasil pengujian ditunjukan pada Tabel 3.3. Penyimpangan kerataan pada bidang "V" bagian dalam ditunjukan pada gambar 3.3.

Tabel 3.3. Data hasil pengujian bidang "v" bagian dalam
\begin{tabular}{|c|c|c|c|}
\hline \multirow{3}{*}{ Titik } & \multicolumn{3}{|c|}{$\begin{array}{c}\text { Data Hasil Pengukuran dengan } \\
\text { Menggunakan Dial Indicator }\end{array}$} \\
\cline { 2 - 4 } & $\begin{array}{c}\text { Hasil } \\
\text { Pengukuran }\end{array}$ & $\begin{array}{c}\text { Kedalaman } \\
\text { Pemakanan }\end{array}$ & Penyimpangan \\
\hline $10 \mathrm{~cm}$ & $0,06 \mathrm{~mm}$ & $0,03 \mathrm{~mm}$ & 0 \\
\hline $20 \mathrm{~cm}$ & $0,06 \mathrm{~mm}$ & $0,02 \mathrm{~mm}$ & $+0,01 \mathrm{~mm}$ \\
\hline $30 \mathrm{~cm}$ & $0,07 \mathrm{~mm}$ & $0,01 \mathrm{~mm}$ & $+0,02 \mathrm{~mm}$ \\
\hline
\end{tabular}

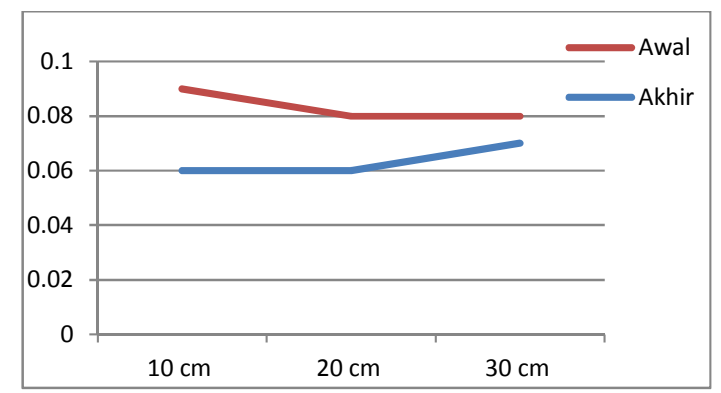

Gambar 3. 3 Grafik penyimpangan Kerataan

\subsection{Hasil Pengujian Kerataan Bidang "V" Bagian Luar}

Dari hasil pengukuran slideway bidang "V" bagian luar slideways nilai yang didapatkan pada pengukuran awal sepanjang $10 \mathrm{~cm}$ dengan hasil pengukuan akhir setelah diproses dengan kedalaman pemakanan $0,03 \mathrm{~mm}$ adalah sebesar $0,09 \mathrm{~mm}$, selanjutnya pada titik $20 \mathrm{~cm}$ dengan hasil pengukuran akhir dengan kedalaman pemakanan $0,02 \mathrm{~mm}$ adalah sebesar $0,08 \mathrm{~mm}$, setelah itu pada titik $30 \mathrm{~cm}$ dengan hasil pengukuran akhir dengan pemakanan $0,01 \mathrm{~mm}$ adalah sebesar $0,08 \mathrm{~mm}$, dengan demikian bidang yang di uji tidak sejajar. Hasil Pengujian kerataan pada bidang "V" bagian luar ditunjukan padaTabel 3.4. Sedangkan penyimpangan kerataan bidang terhadap bidang acuan ditunjukan pada gambar 3.4 .

Tabel 3.4 Data hasil pengujian bidang " $v$ " bagian luar

\begin{tabular}{cccc}
\hline \multirow{2}{*}{ Titik } & \multicolumn{3}{c}{ Data Hasil Pengukuran dengan } \\
& \multicolumn{3}{c}{ Menggunakan Dial Indicator } \\
\cline { 2 - 4 } & Hasil & Kedalaman & Error \\
\hline $10 \mathrm{~cm}$ & $0,09 \mathrm{~mm}$ & $0,03 \mathrm{~mm}$ & 0 \\
\hline $20 \mathrm{~cm}$ & $0,08 \mathrm{~mm}$ & $0,02 \mathrm{~mm}$ & $+0,01 \mathrm{~mm}$ \\
\hline $30 \mathrm{~cm}$ & $0,08 \mathrm{~mm}$ & $0,01 \mathrm{~mm}$ & $+0,02 \mathrm{~mm}$ \\
\hline
\end{tabular}




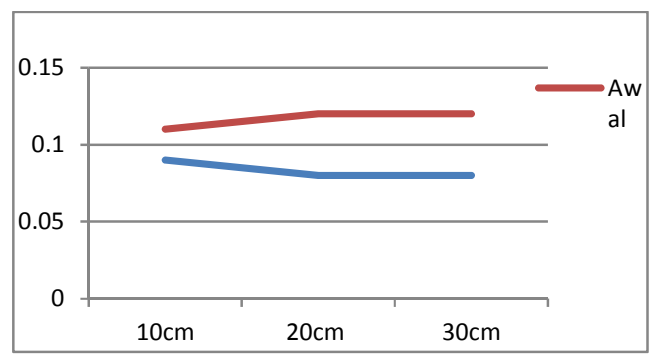

Gambar 3. 4 Grafik Penyimpangan Kerataan

\subsection{Hasil Pengujian Bidang Datar}

Dari hasil pengukuran slideway bidang "V" bagian dalam slideways nilai yang didapatkan pada pengukuran awal sepanjang $10 \mathrm{~cm}$ dengan hasil pengukuan akhir setelah diproses dengan pemakanan $0,03 \mathrm{~mm}$ adalah sebesar $0,09 \mathrm{~mm}$, selanjutnya pada titik $20 \mathrm{~cm}$ dengan hasil pengukuran akhir dengan pemakanan $0,02 \mathrm{~mm}$ adalah sebesar $0,09 \mathrm{~mm}$, setelah itu pada titik $30 \mathrm{~cm}$ dengan hasil pengukuran akhir dengan pemakanan $0,03 \mathrm{~mm}$ adalah sebesar 0,09. dengan demikian bidang yang di uji tercapai dari segi kerataan, kesejajaran dan kerataan. Hasil pengujian kerataan terhadap bidang datar ditunjukan pada Tabel 3.5. Sedangkan penyimpangan kerataan terhadap bidang acuan ditunjukan pada gambar 3.5.

Tabel 3.5 Hasil pengujian bidang datar

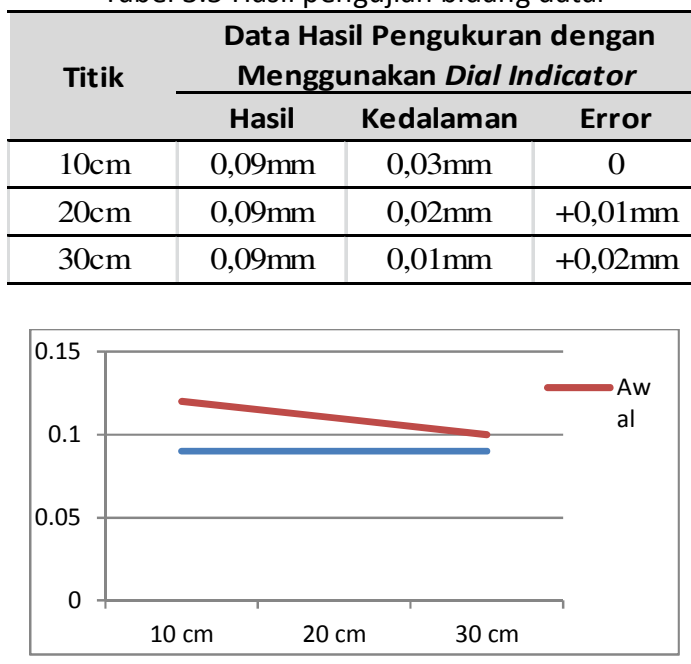

Gambar 3. 5Penyimpangan Kerataan Bidang datar

\section{SIMPULAN}

Berdasarkan pembahasan pada bab sebelumnya, dapat ditarik beberapa kesimpulan, yaitu :

1. Alat Bantu Penggerindaan Slideway Mesin Bubut mampu menggerinda 3 bidang dalam 1 proses menggunakan plat siku dengan $30 \mathrm{~cm}$ sebagai media uji coba pengganti slideway pada mesin bubut.

2. Hasil percobaan pengerindaan pada ketiga bidang slideways dengan kedalaman pemakanan sebesar $0,03 \mathrm{~mm}$, rata - rata nilai kerataan dan kesejajaran didapat sebesar $0,02 \mathrm{~mm} / 300 \mathrm{~mm}$ dan $0,07 \mathrm{~mm} / 300 \mathrm{~mm}$.

\section{DAFTAR PUSTAKA}

[1]. 4GSR, Lathe Way Grinder In Action [Online], diakses tanggal 15 Mei 2017, Available : https://www.youtube.com/watch?v=7NGEQFJdmo4.

[2]. Leo Sichel, "Portable Slideway Grinder", US paten: America US 2,524,332 A,1947.

[3]. Otto Bretsch, "Slideway Grinding Mechine", US patent: America US 2,869,288 A,1959.

[4]. Otto Bretsch, "Slideway Grinding Machine", US patent: America US 2,969,620 A,1961. 